\title{
Antioxidant Enzyme Responses to Hyperoxia in Preterm and Term Rats after Prenatal Dexamethasone Administration
}

\author{
SUSAN E. KEENEY, MARY J. MATHEWS, AND DAVID K. RASSIN \\ Division of Perinatal Pediatrics, Department of Pediatrics, The University of Texas Medical Branch at Galveston. \\ Galveston, Texas 77550)
}

\begin{abstract}
ABSTRACI. Although prenatal steroid therapy is known to enhance in utero maturation of the surfactant and antioxidant enzyme systems, little is known about the effects of steroids on the antioxidant system after birth. We measured activities of the antioxidant enzymes, catalase, superoxide dismutase, and glutathione peroxidase, in lung homogenates from both preterm and term rat pups after prenatal dexamethasone treatment. Enzyme activities were measured at birth and after exposure to $\mathbf{8 9 8 \%}$ oxygen. Dexamethasone treatment resulted in significantly higher survival of the preterm pups at $24 \mathrm{~h}(\mathbf{9 1 . 3 \%}$ for dexamethasone versus $57 \%$ for saline). In preterm pups, the activities of catalase and superoxide dismutase at birth were higher after dexamethasone treatment $(\boldsymbol{p}<\mathbf{0 . 0 5})$. However, after $24 \mathrm{~h}$ of hyperoxic exposure, there were no differences in activities of any of the antioxidant enzymes between the dexamethasone and control groups of prematurely born pups. In term pups, antioxidant enzyme activities did not differ significantly at birth; nor did they differ after 24 to $72 \mathrm{~h}$ of hyperoxic exposure in the dexamethasone and control treatment groups. Our results indicate that although prenatal dexamethasone treatment augments survival and catalase and superoxide dismutase activities at birth in preterm rat pups, dexamethasone does not result in altered early postnatal antioxidant enzyme activities after exposure to hyperoxia. (Pediatr Res 33: 177-180, 1993)
\end{abstract}

\section{Abbreviations}

CAT, catalase

SOD, superoxide dismutase

GPX, glutathione peroxidase

The antioxidant enzyme system serves to protect the organism from $\mathrm{O}_{2}$-free radicals that are produced as a result of breathing and metabolizing ambient $\mathrm{O}_{2}$. Production of free radicals increases after exposure to hyperoxic conditions (1), and oxygen tolerance is thought to depend primarily on the capacity to augment antioxidant enzyme activities in response to hyperoxia (2-5). This capacity to increase antioxidant enzymes may account for the greater $\mathrm{O}_{2}$ tolerance of term neonatal animals of several species compared with adults, even though baseline an-

Received June 3. 1992: accepted October 14, 1992.

Correspondence and reprint requests: Susan E. Keeney, M.D. Division of Perinatal Pediatrics. Department of Pediatrics, University of Texas Medical Branch. Galveston. TX 77550

Supported by the American Lung Association (Basic Research Grant) and a Child Health Research Center grant (HD 27841 Center Grant) from the National Institute of Child Health and Human Development. tioxidant enzyme activities of the neonate tend to be lower ( 6 . 7). Recent studies in rabbits indicate that, compared with animals born at term, preterms demonstrate both lower $\mathrm{O}_{2}$ tolerance and a diminished ability to respond to hyperoxia with increases in antioxidant enzyme activities (8).

Activities of the antioxidant enzymes, CAT, SOD, and GPX. increase in the last 10 to $15 \%$ of gestation $(9-12)$. It has been demonstrated that prenatal administration of dexamethasone causes not only increased maturation of the surfactant system. but also increases in antioxidant enzyme activities in the fetus (13). However, because augmentation of enzyme activities in response to hyperoxia may be necessary for tolerance, the effect of prenatal dexamethasone on postnatal enzyme responses to hyperoxia may be more important than its ability to increase baseline activities in fetal animals.

To our knowledge, there is only one preliminary report of antioxidant enzyme responses to hyperoxia in term neonatal animals after prenatal dexamethasone treatment (14) and no studies in preterm animals. The present study was undertaken to investigate whether there are differences after prenatal dexamethasone treatment in the activities of the pulmonary antioxidant enzymes at birth or after short-term hyperoxic exposure of both preterm and term rats.

\section{MATERIALS AND METHODS}

Animals. For studies of term pups, timed-gestation pregnant Sprague-Dawley rats weighing 250 to $300 \mathrm{~g}$ were obtained from Sasco Inc. (Houston, TX) at gestational d 16 to 17 and were allowed to spontaneously deliver at term $(21.5 \mathrm{~d})$. Pregnant females were given injections of dexamethasone sodium phosphate $0.2 \mathrm{mg} / \mathrm{kg}$ (Elkins-Sinn, Inc.. Cherry Hill, NJ) intramuscularly on d 19 and 20 of gestation. Controls were given injections of an equal volume of $0.9 \% \mathrm{NaCl}$ (saline). Pups from similar treatment groups were pooled and split between $\mathrm{O}_{2}$ and air exposure groups.

For preterm studies, pregnant rats were given injections of dexamethasone on d 18 and 19 (24 and $48 \mathrm{~h}$ before scheduled preterm delivery). On d 20 (24-36 h before expected term gestation), the females were anesthetized with ketamine $80 \mathrm{mg} /$ $\mathrm{kg}$ (Ketalar, Parke Davis, Morris Plains, NJ) and xylazine $4 \mathrm{mg} /$ kg (Gemini TM, Rugby Labs, Inc., Rockville Center, NY). A vertical abdominal incision was made, and the pups were delivered along with the placentas. After delivery of all pups, the umbilical cords were tied with suture and the placentas removed. Pups were washed in warm water and stimulated for a period of 10 to $15 \mathrm{~min}$ to establish respiration. They were placed in exposure chambers with a surrogate mother who had spontaneously delivered at term on the same day. For exposures of preterm pups, the entire $\mathrm{O}_{2}$ exposure cage was placed in an infant incubator (model C86, Air Shields, Inc., Hatboro, PA) with the temperature set to 26 to $27^{\circ} \mathrm{C}$. 
Gas exposures. Exposures to either $\mathrm{O}_{2}$ or air were performed in air-tight plastic cages. $\mathrm{O}_{2}$ and air were humidified and provided at flow rates of $5.0 \mathrm{~L} / \mathrm{min} . \mathrm{O}_{2}$ concentration exiting the cage was analyzed continuously with a Ventronics (Temecula, CA) model $5524 \mathrm{O}_{2}$ monitor. $\mathrm{O}_{2}$ concentrations remained at $\geq 98 \%$ at all times. $\mathrm{CO}_{2}$ exiting the cage was verified to be $<1 \%$ using a Fyrite test kit (Bacharach Inc., Pittsburgh, PA).

All preterm pups were exposed to $\mathrm{O}_{2}$ for $24 \mathrm{~h}$. Term pups were exposed for 24,48 , or $72 \mathrm{~h}$ to either $\mathrm{O}_{2}$ or air. Pups were allowed to nurse ad libitum during gas exposures. Dams were allowed free access to water and rat food during exposures, were maintained on a 12-h light-dark cycle, and were switched between $\mathrm{O}_{2}$ and air exposure groups every $24 \mathrm{~h}$. All experiments were performed with the approval of the Animal Care and Use Committee of the University of Texas Medical Branch.

Preparation of lung homogenates. After anesthesia with sodium pentobarbital, the chest and abdomen were opened, the aorta transected, and the pulmonary artery perfused via the right ventricle with ice-cold PBS, $\mathrm{pH} 7.4$, until the lungs were white. The lungs were then excised from the heart and major bronchi and copiously rinsed with PBS. The lungs were suspended in 5 volumes (wt/vol) of homogenization buffer $(50 \mathrm{mM}$ potassium phosphate buffer, $1.0 \mathrm{mM}$ EDTA, pH 7.4) and homogenized on ice for 1 min on setting 7 in a Brinkmann Polytron (Brinkmann Instruments, Inc., Westbury, NY). The homogenate was then sonicated on ice for $40 \mathrm{~s}$ after addition of Triton X-100 to a final concentration of $0.005 \%$, centrifuged at $20000 \times g$ for $15 \mathrm{~min}$ at $4^{\circ} \mathrm{C}$, and the supernatant solution was frozen at $-70^{\circ} \mathrm{C}$ until assayed for enzyme activity.

Biochemical assays. Activities of the antioxidant enzymes were measured as previously reported (15) using standard spectrophotometric methods. GPX activity was measured using the method of Paglia and Valentine (16) ( 1 unit $=\mathrm{nmol} \mathrm{NAPH} / \mathrm{min})$, CAT was assayed by the method of Holmes and Masters (17) $(1 \mathrm{U}=$ $\left.\mu \mathrm{mol} \mathrm{H}_{2} \mathrm{O}_{2} / \mathrm{min}\right)$, and SOD was assayed using the method of Crapo et al. (18). One unit of SOD activity was defined as that amount of activity causing a $50 \%$ decrease in the rate of cytochrome $c$ reduction/min. DNA was measured spectrophotometrically using the method of Richards (19) with calf thymus DNA as standard. The DNA measurements were repeated due to initial instrument malfunction and therefore were measured after a storage time of longer than $1 \mathrm{mo}$. Blood contamination of lung homogenates was estimated by measuring $\mathrm{Hb}$ concentration using a commercially available kit (Sigma Chemical Co., St. Louis, MO). Blood contamination accounted for $3.26 \pm 0.46 \%$ of SOD activity, for $5.29 \pm 0.81 \%$ of CAT, and $0.79 \pm 0.08 \%$ of GPX activity. These activities are similar to those previously reported (10).

Statistical analysis. Data are expressed as mean \pm standard error of enzyme activities. The lungs of three to six neonatal rats were pooled for each lung homogenate measurement. The homogenates from three to seven litters were analyzed in each group. Probabilities of differences between groups were estimated by the Mann-Whitney nonparametric test (20) unless otherwise specified. Differences between groups of $p<0.05$ were considered to be statistically significant.

\section{RESULTS}

Mortality and body growth. In the preterm groups, mortality within the first 30 min of life (early mortality) was attributed to delivery complications with failure of resuscitation. Mortality in the first $30 \mathrm{~min}$ of life was higher in the dexamethasone than in the control group ( $p=0.0494)$. Thereafter, mortality in the $\mathrm{O}_{2-}$ exposed preterm pups was lower for dexamethasone-treated animals $(91 \%)$ compared with saline controls $(57 \%)$ (Table 1). In the saline-treated (control) groups, survival of preterm pups exposed to air was only $4 \%$ at $24 \mathrm{~h}$ compared with a survival of $57 \%$ in $\mathrm{O}_{2}$. Although survival in the $\mathrm{O}_{2}$ saline group was $57 \%$ after $24 \mathrm{~h}$, it diminished markedly between 48 and $72 \mathrm{~h}(12 \%$ at $72 \mathrm{~h})$. Birth weights of preterms did not differ between the dexamethasone and control groups. Weight loss in preterm pups was observed over the 24-h study period, presumably because of poor nutrition, but the degree of weight loss did not differ between the treatment groups.

The pups born at term had negligible mortality over the 72-h study period regardless of prenatal treatment or type of exposure. Birth weights at term were significantly lower in the dexamethasone group (Table 1), suggesting a steroid effect on prenatal growth. However, weight gains for the term groups at 24 and 72 $h$ did not differ between treatment or exposure groups.

Due to the potential inaccuracy of lung weights after pulmonary artery perfusion, we did not routinely measure weights of individual lungs.

Antioxidant enzyme activities in lung homogenates of preterm pups at birth and after hyperoxic exposure. At birth, the dexamethasone-treated preterm pups had significantly higher CAT and SOD activities than controls (Fig. 1). There were no differences in GPX at birth between the two prenatal treatment groups, although GPX tended to be lower in the dexamethasone group.

In preterms, after $24 \mathrm{~h}$ of hyperoxia, activities of the enzymes did not differ between the dexamethasone and control treatment groups. Compared with activities at birth. CAT and SOD increased 23 and $28 \%$, respectively ( $p<0.05$ for SOD), after $24 \mathrm{~h}$ of hyperoxic exposure in the control (saline-treated) preterm pups (Fig. 1), whereas there was no change in GPX. Alternatively, in the dexamethasone group, GPX was higher after $24 \mathrm{~h}$ of hyperoxia, but there were no changes in SOD and CAT.

Antioxidant enzyme activities in term rat pups at birth and after hyperoxic exposure. In term pups, there were no differences in antioxidant enzyme activities at birth between the dexamethasone and control treatment groups (Fig. 2). In the air-exposed term pups, both CAT and GPX activities rose to a maximum at $48 \mathrm{~h}$, whereas SOD did not change. Although there were trends toward higher activities of SOD and CAT in the dexamethasonetreated group after exposure to air for 24 and $72 \mathrm{~h}$. differences were significant only for SOD at $72 \mathrm{~h}(p<0.05)$. After hyperoxic exposure of term pups (Fig. 2), there were no differences in antioxidant enzyme activities between the dexamethasone and control groups.

\section{DISCUSSION}

We have examined antioxidant enzyme activities at birth and after hyperoxic exposure in both preterm and term rat pups after

Table 1. Mortality and hody growth in prenatal treatment groups at $0-24 \mathrm{~h}$

\begin{tabular}{lcccc}
\hline & $\begin{array}{c}\text { \% Early mortality } \\
(<30 \mathrm{~min})\end{array}$ & $\begin{array}{c}\text { \% Late mortality } \\
(24 \mathrm{~h})\end{array}$ & $\begin{array}{c}\text { Birth weight* } \\
(\mathrm{g})\end{array}$ & $\begin{array}{c}\text { Weight change* } \\
(24 \mathrm{~h})\end{array}$ \\
\hline Preterm saline & $0 / 48 \dagger$ & $13 / 30(43 \%) \ddagger$ & $4.41 \pm 0.09$ & $-0.49 \pm 0.07$ \\
Preterm dexamethasone & $5 / 65(7.7 \%) \S$ & $4 / 46(8.7 \%) \S$ & $4.47 \pm 0.31$ & $-0.51 \pm 0.19$ \\
Term saline & $0 / 85$ & $0 / 47$ & $6.13 \pm 0.15$ & $+1.34 \pm 0.21$ \\
Term dexamethasone & $2 / 55(3.6 \%)$ & $0 / 38$ & $5.67 \pm 0.20 \$$ & $+0.73 \pm 0.24$ \\
\hline
\end{tabular}

* Values expressed as mean \pm SEM.

+ The denominator denotes the number of pups born.

$\ddagger$ The denominator denotes the number of pups in the 24-h study groups.

$\$ p<0.05$ for saline is dexamethasone within each age group by $\chi^{2}$ analysis (mortality) and $t$ test (weights). 
A

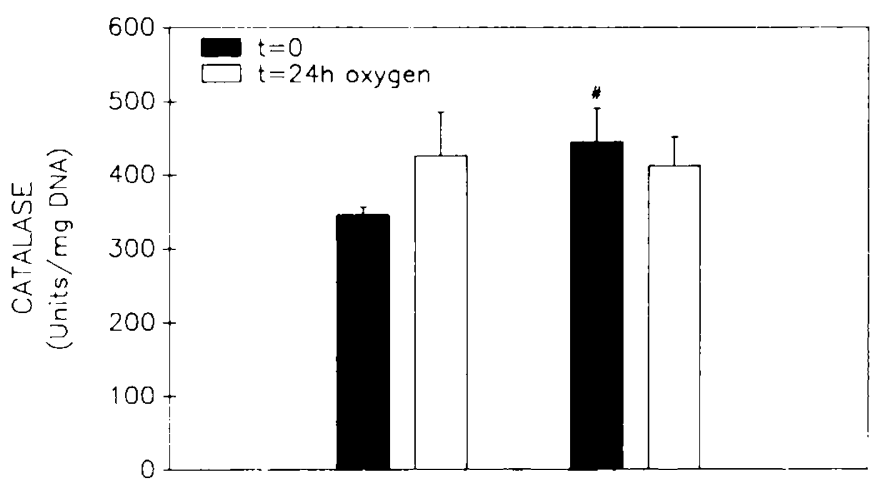

B

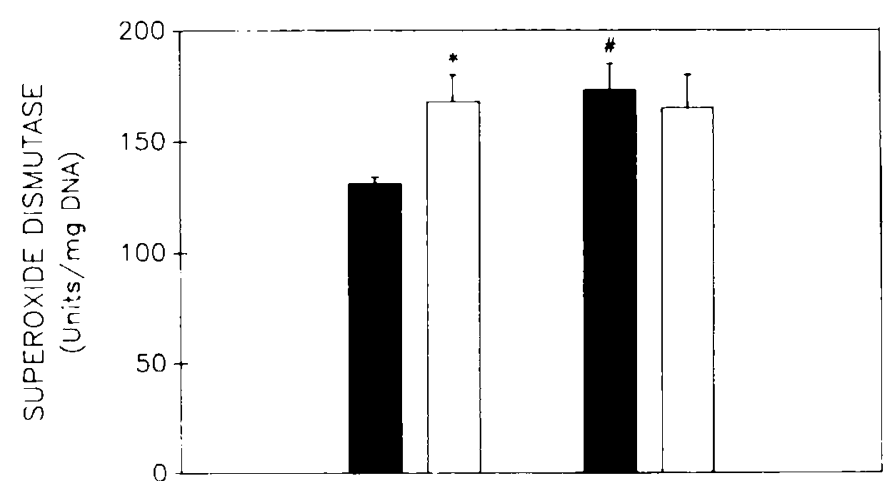

C

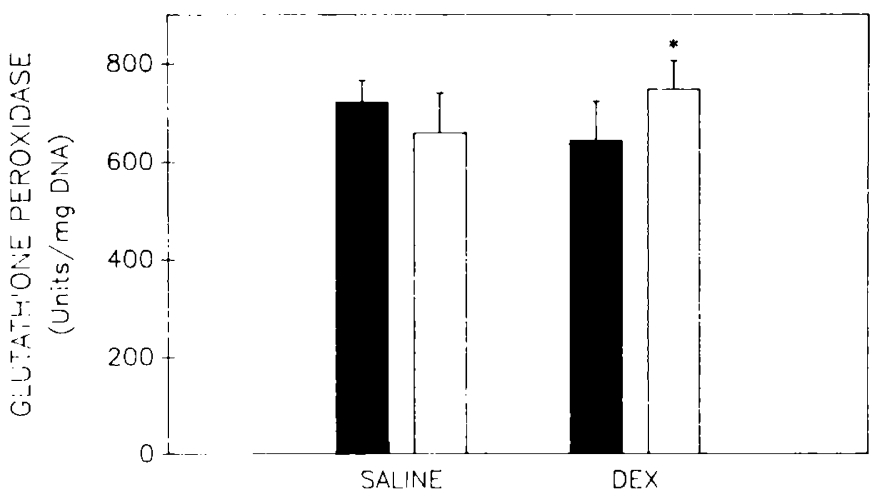

Fig. 1. Comparison of CAT (A), SOD $(B)$, and GPX $(C)$ at birth (t $=0)$ and after $24 \mathrm{~h}$ of $>95 \% \mathrm{O}_{2}$ exposure $(\mathrm{t}=24)$ in preterm rat pups treated prenatally with saline or with dexamethasone. Activities are expressed as mean units/mg DNA \pm SEM for four separate exposures in each of the groups at birth and in the saline group at $24 \mathrm{~h}$ and for seven exposures in the dexamethasone group at $24 \mathrm{~h}:{ }^{*} . l<0.05$ for $\mathrm{t}=0 \mathrm{ust}$ $=24$ within each prenatal treatment group: \#. $p<0.05$ for saline $v$ dexamethasone treatment.

prenatal dexamethasone treatment. To our knowledge, this is the first report of antioxidant enzyme activities after hyperoxia in the preterm rat or of the early $(<7 \mathrm{~d})$ response of term neonatal rats to hyperoxia after prenatal dexamethasone treatment.

A shortcoming of the study was the inability to include a control group of preterm animals exposed to air or a group of preterm animals exposed to hyperoxia for $>24 \mathrm{~h}$. Tanswell $e t$ al. (21) reported similar mortality rates in air-exposed preterm pups, with only a $6 \%$ survival at $24 \mathrm{~h}$. Their reported survival of $\mathrm{O}_{2}$ exposed pups at $36 \mathrm{~h}$ was $47 \%$, which was similar to ours $(57 \%$ at $24 \mathrm{~h}$ ). These survivals are also similar to those reported by Frank et al. (13) of 9\% 6-h survival in $40 \% \mathrm{O}_{2}$. However, Tanswell et al. (21) reported negligible mortality after $36 \mathrm{~h}$, until
A

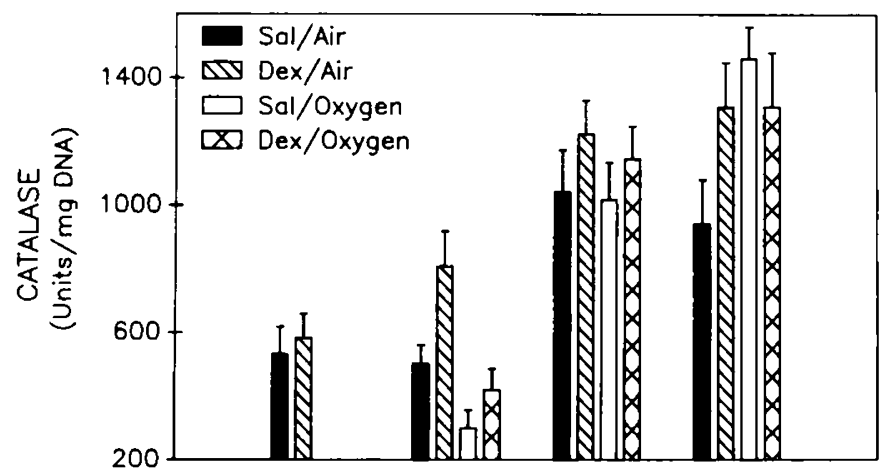

B

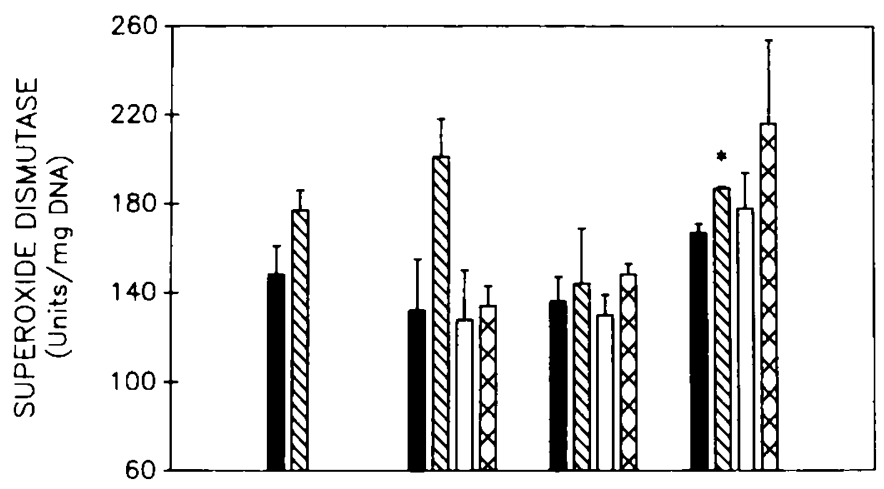

C

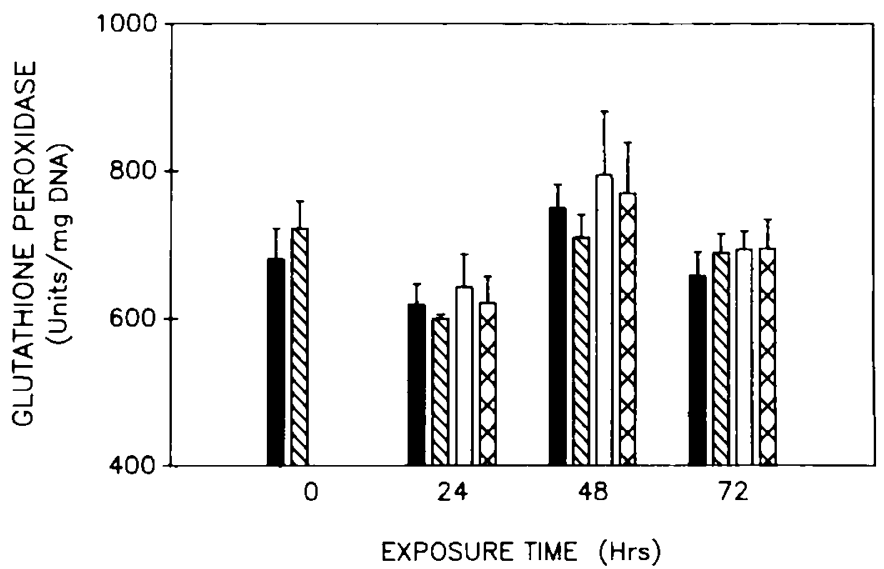

Fig. 2. Activities of CAT (A). SOD $(B)$, and GPX ( $\left(C^{\prime}\right)$ at birth $(\mathrm{t}=$ 0 ) and after 24.48. and $72 \mathrm{~h}$ of exposure to air or $>98 \% \mathrm{O}_{2}$ in term rat pups. Activities are expressed as mean units/mg DNA \pm SEM for three to six separate exposures. ${ }^{*} . p<0.05$ for saline/air (Sal/Air) is dexamethasone/air ( $D(x / t i r)$. There were no differences in activities between treatment groups after hyperoxic exposure. Filled hars, control (saline treatment) at birth and after 24 to $72 \mathrm{~h}$ of air exposure: diagonally. hatched hars, dexamethasone-treated pups at birth and after air exposure: open hars, control after $\mathrm{O}_{2}$ exposure for 24 to $72 \mathrm{~h}$ : cross-hatched hars. dexamethasone after $\mathrm{O}_{2}$ exposure.

the 2 nd wk of life. In contrast. our group of preterm rats demonstrated substantial mortality between 48 and $72 \mathrm{~h}$. This may be explained by slight differences in pulmonary maturity. The birth weights of the preterm rats in our control group were less than previously reported birth weights for rats born $24 \mathrm{~h}$ prematurely (4.41 versus 5.39) (13), suggesting more immaturity. Therefore, the results of study of the saline control group must be interpreted with caution because the survivors may include a group with slightly more pulmonary maturity. However, it is doubtful that it is a group more inherently resistant to $\mathrm{O}_{2}$ toxicity. 
In term neonates at least, $\mathrm{O}_{2}$-induced mortality begins at about $7 \mathrm{~d}(6)$, and Tanswell et al. (21) reported that $\mathrm{O}_{2}$ injury did not occur until the 2 nd wk of life in preterm pups.

Our findings of higher SOD and CAT at birth in the dexamethasone preterm groups corroborates a previous report by Frank et al. (13). However, the higher activities at birth were not maintained postnatally, and there were no differences between the treatment groups after hyperoxia.

Over the 24-h exposure of the saline control group, there was a significant rise in SOD and a trend toward an increase in CAT, as well. Because we were unable to study a group of air controls, we could not determine whether this was a response to hyperoxia. These postnatal changes may reflect the in utero rise in lategestational enzyme activities previously documented in the rat fetus (9-13). However, because there was a high mortality in this group at $24 \mathrm{~h}$, conclusions are difficult to make. There are no previous studies of postnatal changes in antioxidant enzyme activities in preterm lungs, except in the rabbit. Frank and Sosenko (8) demonstrated no differences in antioxidant enzyme activities after 48 and $72 \mathrm{~h}$ of $\mathrm{O}_{2}$ compared with air exposure in the preterm rabbit, suggesting that preterm rabbits do not respond to hyperoxia with increases in antioxidant enzyme activities. They did not report changes in activities from birth to 48 or $72 \mathrm{~h}$, nor did they study prenatal dexamethasone treatment, so their results cannot be compared with those of the present study.

Of interest is the appearance of a coordinate regulation of CAT and SOD compared with GPX in the preterm groups. Prenatal dexamethasone resulted in higher SOD and CAT at birth, but no change in GPX. After 24 h of hyperoxic exposure, GPX increased in the dexamethasone-treated group, whereas at least SOD increased in the saline group. SOD and CAT are both necessary for complete detoxification of superoxide anion, and coordinate changes in these enzymes would theoretically allow more efficient antioxidant protection.

Our results confirm a previous report that prenatal treatment with dexamethasone does not result in differences in antioxidant enzyme activities at birth in term rats (13). Although there were trends toward higher CAT and SOD activities in dexamethasonetreated term pups after both air and $\mathrm{O}_{2}$ exposure, these differences did not reach significance except for SOD after $72 \mathrm{~h}$ of air exposure. Similarly, preliminary data from Frank (14), who studied term rats after longer durations of $\mathrm{O}_{2}$ exposure $(7-10 \mathrm{~d})$, indicate that prenatal dexamethasone treatment does not result in a later augmentation of enzyme response. Of interest, Frank (14) also reported improved survival under hyperoxic conditions in the dexamethasone-treated term rats. Mechanisms other than the antioxidant enzyme system may be involved in improved survival. Prenatal dexamethasone treatment may result in diminished oxidative stress due to its antiinflammatory effects $(22)$, or it may accelerate maturation of the relatively immature lung structure of the term rat (23-27), thereby improving $\mathrm{O}_{2}$ tolerance.

In summary, prenatal dexamethasone treatment dramatically improved survival of preterm pups at $24 \mathrm{~h}$. Although prenatal dexamethasone enhances the maturation of the antioxidant enzyme system in late gestation, there were no differences between the treatment groups in enzyme activities after hyperoxia. Although prenatal dexamethasone may protect the term neonate from $\mathrm{O}_{2}$ toxicity (14), our data suggest that early augmentation of antioxidant enzyme activities in term neonatal rats does not accompany this phenomenon. Further investigation of the effects of prenatal dexamethasone on the lungs of neonatal animals exposed to high $\mathrm{O}_{2}$ concentrations is indicated.

Acknowledgments. The authors thank Dr. Constance Baldwin for advice and editing and Janet Catching for assistance with preparation of the manuscript.

\section{REFERENCES}

1. Freeman BA. Topolosky MK. Crapo JD 1982 Hyperoxia increases oxygen radical production in rat lung homogenates. Arch Biochem Biophys 216:477-484

2. Crapo JD. Tierney DF 1974 Superoxide dismutase and pulmonary oxygen toxicity. Am J Physiol 226:1401-1407

3. Crapo JD, Sjostrom K, Drew RT 1978 Tolerance and cross-tolerance using $\mathrm{NO}_{2}$ and $\mathrm{O}_{2}$ : I. Toxicology and biochemistry. J Appl Physiol 44:364-369

4. Coursin DB, Cihla HP, Will JA, McCreary JL 1987 Adaptation to chronic hyperoxia: biochemical effects and the response to subsequent lethal hyperoxia. Am Rev Respir Dis 135:1002-1006

5. Frank, L 1985 Oxygen toxicity in eukaryotes. In: Oberley LW (ed) Superoxide Dismutase. Vol III. CRC Press, Boca Raton, FL, pp 2-34

6. Frank L, Bucher JR, Roberts RJ 1978 Oxygen toxicity in neonatal and adult animals of various species. J Appl Physiol 45:699-704

7. Yam J, Frank L, Roberts RJ 1978 Oxygen toxicity: comparison of lung biochemical responses in neonatal and adult rats. Pediatr Res 12:115-119

8. Frank L, Sosenko IRS 1991 Failure of premature rabbits to increase antioxidant enzymes during hyperoxic exposure: increased susceptibility to pulmonary oxygen toxicity compared with term rabbits. Pediatr Res 29:292-296

9. Yam J, Frank L, Roberts RJ 1978 Age-related development of pulmonary antioxidant enzymes in the rat. Proc Soc Exp Biol Med 157:293-296

10. Tanswell AK, Freeman BA 1984 Pulmonary antioxidant enzyme maturation in the fetal and neonatal rat. I. Developmental profiles. Pediatr Res 18:584587

11. Frank L, Groseclose EE 1984 Preparation for birth into an $\mathrm{O}_{2}$-rich environment: the antioxidant enzymes in the developing rabbit lung. Pediatr Res 18:240-244

12. Frank L, Sosenko IRS 1987 Prenatal development of lung antioxidant enzymes in four species. J Pediatr 110:106-110

13. Frank L, Lewis PL, Sosenko IRS 1985 Dexamethasone stimulation of fetal rat lung antioxidant enzyme activity in parallel with surfactant stimulation. Pediatrics 75:569-574

14. Frank L 1991 Prenatal dexamethasone treatment improves tolerance of newborn rats to prolonged high $\mathrm{O}_{2}$ exposure. Pediatr Res 29:317A(abstr)

15. Keeney SE, Cress SE, Brown SE. Bidani A 1992 The effect of hyperoxic exposure on antioxidant enzyme activities of alveolar type II cells in neonatal and adult rats. Pediatr Res 31:441-444

16. Paglia DE, Valentine WN 1967 Studies on the quantitative and qualitative characterization of erythrocyte glutathione peroxidases. J Lab Clin Med 70:158-159

17. Holmes RS, Masters CJ 1970 Epigenetic interconversion of the multiple forms of mouse liver catalase. FEBS Lett 11:45-48

18. Crapo JD, McCord JM, Fridovich I 1978 Superoxide dismutases, preparation and assay. In: Fleischer S, Packer L (eds) Methods of Enzymology. Vol. 53(D). Academic Press, New York, pp 382-393

19. Richards GM 1974 Modifications of the diphenylamine reaction giving increased sensitivity and simplicity in the estimation of DNA. Anal Biochem 357:369-376

20. Kaplan EL, Meier $\mathbf{P} 1958$ Nonparametric estimation from incomplete observations. J Am Stat Assoc 53:457-481

21. Tanswell AK, Wong L, Possmayer F. Freeman BA 1989 The preterm rat: a model for studies of acute and chronic neonatal lung disease. Pediatr Res 25:525-529

22. Tate RM, Repine JE 1983 Neutrophils and the adult respiratory distress syndrome. Am Rev Respir Dis 128:552-559

23. Seidner S, Pettenazzo A, Ikegami M. Jobe A 1988 Corticosteroid potentiation of surfactant dose response in preterm rabbits. J Appl Physiol 64:2366-2371

24. Beck JC, Mitzner W, Johnson JWC. Hutchins GM. Foidart JM. London WT. Palmer AE, Scott R 1981 Betamethasone and the rhesus fetus: effect on lung morphometry and connective tissue. Pediatr Res 15:235-240

25. Kikkawa Y. Kaibara M, Motomaya EK. Orzalesi MM, Cook CD 1971 Morphologic development of fetal rabbit lung and its acceleration with cortisol. Am J Pathol 64:423-442

26. Blanco LN, Massaro GD, Massaro D 1989 Alveolar dimensions and number: developmental and hormonal regulations. Am J Physiol 257:L240-L247

27. Frank L, Roberts RJ 1979 Effects of low-dose prenatal corticosteroid administration on the premature rat. Biol Neonate 36:1-9 